This item was submitted to Loughborough's Research Repository by the author.

Items in Figshare are protected by copyright, with all rights reserved, unless otherwise indicated.

\title{
Editorial: commemorating Einstein's special theory of relativity
}

PLEASE CITE THE PUBLISHED VERSION

PUBLISHER

Professional Engineering Publishing / @ IMECHE

VERSION

VoR (Version of Record)

LICENCE

CC BY-NC-ND 4.0

REPOSITORY RECORD

Rahnejat, Homer. 2019. "Editorial: Commemorating Einstein's Special Theory of Relativity”. figshare. https://hdl.handle.net/2134/4729. 
This item was submitted to Loughborough's Institutional Repository (https://dspace.lboro.ac.uk/) by the author and is made available under the following Creative Commons Licence conditions.

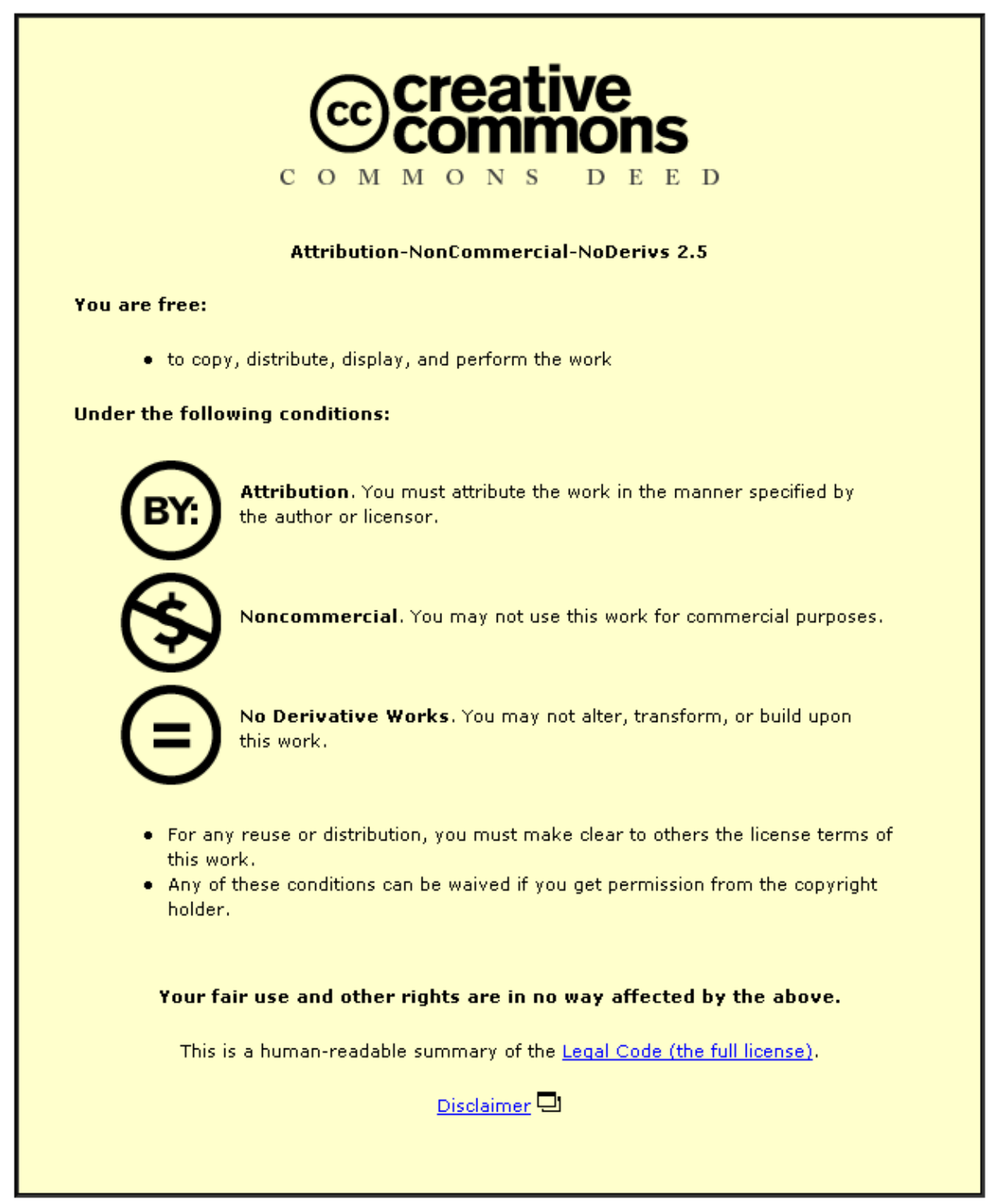

For the full text of this licence, please go to: http://creativecommons.org/licenses/by-nc-nd/2.5/ 


\section{COMMEMORATING EINSTEIN'S SPECIAL THEORY OF RELATIVITY}

This Special Issue of the Journal contains five contributions intended to mark the centenary of the Special Theory of Relativity, expounded by Albert Einstein in 1905, and I am extremely grateful to my learned colleagues for their contributions.

Mendel Sachs, one of the leading theoretical physicists and a major advocate of the theory of relativity, explains the special theory in a very lucid and succinct manner for the largely engineering readers of the Journal. The theory was in many ways the culmination of the study of motion of matter in all its forms. Understanding of the physics of motion constitutes the longest field of scientific endeavour, being one of the main preoccupations of ancient geometers and astronomers, including Homer in the 8th century BC in the various books of the Iliad. During this period many hypotheses and theories have been presented and progress made in an evolutionary manner, often through rationalization of previously stated erroneous postulates. In the recorded and surviving studies of motion for nearly three millennia, a few contributions stand out as truly revolutionary; a matter of debate and persuasion in itself. In my opinion, such contributions are marked by certain shared attributes. They are naturally appealing to everyone, i.e. axiomatic, simple, and yet profound. The Galilean principle of relativity, Newton's law of universal gravitation and his three laws of motion, and the special theory of relativity possess these qualities. The special theory is merely the law of constancy of speed of light in a vacuum, represented by $c=$ constant. It is the simplest law in physics, as Einstein noted

There is hardly a simpler law in physics than that according to which light is propagated in empty space. Every child at school knows, or believes he knows, that this propagation takes place in straight lines. .

Its implications, however, are profound, and indeed immense. For one, it limits physics to its original definition by Aristotle: observation of nature (study of motion within the light cone), and for another it unified Maxwellian electromagnetics with Newtonian kinetics through the use of this simplest law of physics and the Galilean principle of relativity. To achieve this, the simple law described above was replaced by the Lorentzian boost in keeping with the principle of relativity, which itself was declared a law of physics. The adoption of the boost within the special theory has brought about certain adverse repercussions, particularly with regard to the retention of the concept of time as an explicit independent co-ordinate, linked to an event in the vicinity of its spatial location. I have tried to highlight this in my contribution to this issue.

The creation of the linkage between space and time pointed to a continuum, referred to as space-time. This meant that the then prevalent atomism in physics had to give way to the existence of potential fields that belie the fabric of space-time as had already been described for electromagnetics by Michael Faraday and Clerk Maxwell. Einstein was converted to a field theorist by subscribing to the Mach's principle

I was of course acquainted with Mach's view, according to which it appeared conceivable that what inertial resistance counteracts is not acceleration as such but acceleration with respect to the masses of other bodies existing in the world. 
It was through the principles of equivalence and general covariance that Einstein arrived at a field-law for gravitation, curved space-time, and the general theory of relativity. This was the culmination of a quest, initiated by the very simple and profound law, embodied in the special theory. In the words of Einstein the key question in his mind in 1905 was

... if only a relative meaning can be attached to the concept of velocity, ought we nevertheless to persevere in treating acceleration as an absolute concept?

The field-law for gravitation resulted in the description of space-time by a fundamental metric tensor, the concept used by my learned colleagues, Nicolae Orlandea and Rajeev Bhatnagar to treat multi-body dynamics problems using generalized differential geometry in the case of the former, and the flight of ballistics in the case of the latter. My other learned colleague, Peter Maißer, describes various forms of non-Euclidean geometry and creates a metric to combine the electric field with fundamental metric tensor for generic formulation of mechatronics-type problems in his paper.

Homer Rahnejat

Editor-Journal of Multi-body Dynamics 